\title{
An Examination of the Mediating Role for a Nursing Information System
}

\author{
Lemai Nguyen \\ Department of Information Systems and Business Analytics \\ Deakin Business School \\ Deakin University \\ lemai.nguyen@deakin.edu.au
}

\author{
Nilmini Wickramasinghe \\ Health Informatics Management \\ Epworth HealthCare \\ Faculty of Health, \\ Deakin University
}

\section{Abstract}

This paper reports on findings from an examination of a nursing information system through the lens of Activity Theory. The information system was designed to support real-time nursing documentation in acute care hospital contexts. The objective was to enable superior nursing care to ensue by providing nurses with the opportunity to document patient care data into a tablet computer located at the patient bedside. The system was evaluated in a not-for-profit acute care hospital's wards during its implementation. Nurses' interactions with the system and their perceptions were collected and analysed through the lens of Activity Theory. The analysis highlighted nurses' positive attitude towards the system and identified potential mediation capabilities as well as areas for improvements. Activity Theory was found to be useful to examine the positive and potentially problematic aspects of this new nursing information system.

Keywords: Activity theory; nursing informatics; health information systems; electronic documentation.

\section{Introduction}

Increasingly health information systems (HIS) are introduced into healthcare as a mediating tool to support patient care delivery and to improve care quality, safety and efficiency. The introduction of HIS comes with many challenges. These are due to the dynamic and complex nature of healthcare operations; such as multi-disciplinary characteristics of critical tasks, the high stakes of life and death, the tensions between orderly routines and the need for flexibility, the need to combine rationale and intuitive judgement in key decision making, and various organisational and regulatory setting specifications (Fichman et al., 2011; Shaban, 2005; Thompson \& Dowding, 2002: chapter 1). In such a complex context, a good understanding of the mediating role of technology, i.e. whether and how it can support the clinician user in care delivery, is important to facilitate successful HIS design, implementation and adoption as well as support superior care delivery.

Over the years, on-going research reports mixed and inconclusive results in regard to impacts of HIS implementation and its assimilation to clinicians' practice and workflow (Lau et al., 2010; Mills et al., 2013; Nguyen et al., 2014). Industry surveys conducted by the American College of Physicians and American EHR Partners (2013) reveal an overall dissatisfaction of the clinician users. Moreover, these reports highlight a need for a rich understanding of the role of HIS with the clinicians' in the context of their activities and practice. The research reported in this paper contributes to addressing this need by examining the potential mediating role of a new HIS in an acute healthcare setting for front line clinical staff, particularly nurses. In order to do so, Activity Theory (Engeström, 1999; Vygotsky, 1978) was selected as a suitably rich theoretical lens to understand the interactions between individuals, 
their goals, and the mediating tool to achieve a specific outcome; namely better patient care. Specifically in this study, Activity Theory serves as a lens to examine the interactions between the Nurse, the Nursing documentation, and a new Electronic Bedside Documentation System (EBDS) to improve patient care delivery.

The paper is structured as follows. Section 2 provides a background discussion about nurses and information systems. Section 3 provides an overview of the key concepts in Activity Theory and its use in the information systems discipline. Section 4 describes the adopted research approach. Section 5 presents the results of the study. Section 6 concludes the paper with a summary of the key findings, theoretical and practical implications, limitations and future research directions.

\section{Nurses and information systems}

In healthcare delivery, nurses provide front-line and continuous care for patients. They play a key role in patient safety including early detection of deterioration and prevention of complications such as pressure injuries, falls and infections (see for example, Cornell et al., 2010; Courtney et al., 2005; Hegney et al., 2007). Previous research has provided robust evidence of the relationship between the quality of nursing care and patient outcomes (Australian Nursing Federation, 2009; Rafferty et al., 2007). The nursing process includes assessment, diagnosis, planning, implementation, and evaluation (Timby, 2009: chapter 2). This process involves various observations, decision-making, and interventions and associated patient health outcomes. Nursing documentation is essential in keeping accurate records of delivered care and patient health status, as well as supporting clinical communication about nurses' observations, decisions, actions and outcomes. Not only is nursing documentation a legal requirement, it promotes the early identification of patient health issues and opportunities for care quality and safety improvements. Nursing documentation is a routine, integral part of safe and effective patient care delivery (Blair \& Smith, 2012).

With the advancements of portable computers and electronic health records, electronic bedside documentation systems are increasingly introduced to nurses as a support tool for nursing documentation. The objective is to enable nurses to document and access patient care data at the patient bedside when care is delivered. Common anticipated benefits include increased care quality, patient safety and process efficiency as a result of better access to realtime and accurate patient data. The reality has yet to reach this state and over one decade (2003-2014) of literature reviews report mixed findings including attitude of nurses toward adopting technology solutions and impacts of technology adoption in healthcare (Häyrinen et al., 2008; Lau et al., 2010; Meijden et al., 2003; Mills et al., 2013; Nguyen et al., 2014). Mixed findings are still found in recent research (Lin et al., 2016; Tilahun \& Fritz, 2015).

Nurses' low satisfaction with system' usability and fidelity of technology solutions in their practice emerge frequently as two strong themes in previous research. Usability has been defined in ISO 9241 as "the extent to which a product can be used by specified users to achieve specified goals with effectiveness, efficiency and satisfaction in a specified context of use" (International Organization for Standardization, 1998). In this paper, fidelity refers to the system's appropriateness or fitness with the context of use. Table 1 summarises findings from previous research in relation to these themes. We note that while other issues such as security, networks, and other characterises of selected technologies are also important they are not considered in this study since in general for acute healthcare contexts if usability and fidelity are problematic, these other issues are not considered or treated as mute until usability and fidelity are addressed. 


\begin{tabular}{|c|c|c|}
\hline \multirow{4}{*}{$\begin{array}{l}\text { Themes } \\
\text { Usability }\end{array}$} & \multicolumn{2}{|c|}{ Summary of findings } \\
\hline & $\begin{array}{l}\text { Ease of use / } \\
\text { Efficiency }\end{array}$ & $\begin{array}{l}\text { Complex user-interface and navigation mechanism, slow response, poor } \\
\text { content design (Darbyshire, 2004; Kossman, 2006; Lee et al., 2008; } \\
\text { Stevenson et al., 2010; Vatnøy et al., 2014; Weinhara et al., 2009; } \\
\text { Whittaker et al., 2009). } \\
\text { Moderate ease of use (Weinhara et al., 2009; Whittaker et al., 2009). } \\
\text { Observed increased time spent on direct patient care and nursing } \\
\text { documentation, and decreased time spent on administrative tasks } \\
\text { (Banner \& Olney, 2009) in contrast to no significant change in time } \\
\text { spent on patient care (Westbrook et al., 2013). }\end{array}$ \\
\hline & $\begin{array}{l}\text { Usefulness / } \\
\text { Effectiveness }\end{array}$ & $\begin{array}{l}\text { Perceived usefulness: access to important patient care information and } \\
\text { reduced written documentation (Hoonakker et al., 2013; Kossman, } \\
\text { 2006; Vatnøy et al., 2014; Whittaker et al., 2009), improved information } \\
\text { quality (Aktharsha \& Anisa, 2011; Darbyshire, 2004; Tilahun \& Fritz, } \\
\text { 2015), enabled monitoring of patients' health parameters (Miller et al., } \\
\text { 2009). } \\
\text { Some functions were used less relevant, less frequently or never used } \\
\text { (Darbyshire, 2004; Nakamura et al., 2010; Tilahun \& Fritz, 2015). }\end{array}$ \\
\hline & Satisfaction & $\begin{array}{l}\text { Majority of nurses have a moderately positive attitude toward using HIS } \\
\text { (de Veer \& Francke, 2010; Mills et al., 2013; Moody et al., 2004). } \\
\text { Mixed findings: Moderate / high satisfaction (Hoonakker et al., 2013; } \\
\text { Moody et al., 2004). Low satisfactory / dissatisfaction (Darbyshire, } \\
\text { 2004; Lærum et al., 2004; Mills et al., 2013; Stevenson et al., 2010; } \\
\text { Tilahun \& Fritz, 2015). } \\
\text { Dynamics of nurses' experience: During the period of implementation, } \\
\text { nurses' attitude and satisfaction increased overtime as they experienced } \\
\text { more with the system (Ammenwerth et al., 2011; Carayon et al., 2011; } \\
\text { Lee et al., 2008). }\end{array}$ \\
\hline Fidelity & \multicolumn{2}{|c|}{$\begin{array}{l}\text { HIS functionality did not meet the nurses' needs nor support their workflows and practice } \\
\text { (Novak et al., 2013; Stevenson et al., 2010); workflow interruptions, additional work (Eley } \\
\text { et al., 2009; Lee et al., 2008), unintended consequences (Dowding et al., 2009; Koppel et } \\
\text { al., 2005). } \\
\text { A particular HIS may fit one context but not others (Ackerman et al., 2012; Gough et al., } \\
\text { 2014; Jeskey et al., 2011) }\end{array}$} \\
\hline
\end{tabular}

Table 1. Summary of previous research in relation to usability and fidelity

Firstly, in regard to usability, Stevenson et al. (2010) reviewed five empirical studies published from 2000 to 2009 and reported on nurses' experiences with HIS systems. These studies took place in acute care hospital contexts in USA, Australia, and the UK. According to their review, HIS functionality was not useful nor did it meet the nurses' needs nor support their workflow; the user-interfaces were found to be difficult to use and navigate. Overriding of the system, duplication of documentation, and a reversion to familiar systems such as paper recording were reported as major work-around strategies when technology solutions did not meet clinicians' needs (Dowding et al., 2009; Koppel et al., 2005). More recently, Mills et al. (2013) reviewed 21 studies published between 1995 and 2010 which took place in acute care contexts in Australia and New Zealand. As reported in their review, while nurses held positive attitudes toward HIS adoption they experienced dissatisfaction with technology implementations at the workplace. Particularly, nurses reported problems with the system's lack of intuitive userinterface and navigation design, complex content presentation, and slow response (Darbyshire, 2004; Kossman, 2006; Lee et al., 2008; Vatnøy et al., 2014; Weinhara et al., 2009; Whittaker et al., 2009). Contradictory findings were found in two time and motion studies: Banner and Olney (2009) found that nurses spent more time on documentation and direct patient care and less time on administration. In contrast, Westbrook et al. (2013) found no redistribution of time away from direct patient care or other tasks before and after the HIS implementation. Usefulness of HIS was perceived by nurses to include the system's capability to document and access patient care data, improved legibility and reduced data errors (e.g. Aktharsha \& Anisa, 2011; Hoonakker et al., 2013; Vatnøy et al., 2014), and enabled monitoring of patients' parameters (Miller et al., 2009). Mixed findings were reported in regard to nurses' 
satisfaction with HIS. A majority of studies reported low satisfaction or dissatisfaction with HIS (Darbyshire, 2004; Lærum et al., 2004; Mills et al., 2013; Stevenson et al., 2010; Tilahun \& Fritz, 2015). Surveys with nurses 3 months and 12 months after HIS implementation at an US regional medical centre found nurses' satisfaction toward the system increased over time (Carayon et al., 2011).

Secondly, HIS functionality was criticised by nurses for its poor fit with their workflow and practice needs (Darbyshire, 2004; Novak et al., 2013). Novak et al. (2013) observed a collision between nursing and technology frames of references as well as observing nurses' adaptations to fit HIS with their work. HIS was found to cause workflow interruptions and increased workload (Eley et al., 2009; Lee et al., 2008), and unintended consequences (Dowding et al., 2009; Koppel et al., 2005). In addition, a particular HIS may fit one context but not others; the same HIS was successfully adopted in urgent care but was abandoned when it was introduced to routine patient care due to its poor fit (Ackerman et al., 2012). In another study (Jeskey et al., 2011), HIS designed for critical care was found to be unsuitable for acute care settings. Gough et al. (2014) interviewed 125 nurses at five acute care hospitals across two Australian states. They found that HIS supported nurses and enhanced their sense of autonomy at high dependency wards while it increased their workloads and reduced their interactions with patients in low dependency wards. In summary, usability and fidelity are frequently identified and remain on-going strong themes in the literature. As these concern technology's capability and fitness with the context of use, we focus on examining them as mediating roles of technology in nursing documentation activity to see if this could address current key voids noted throughout the literature regarding usability and fidelity.

Having conducted a literature review in electronic health record (EHR) systems as real-time point of care information systems in the context of orders management, Staggers et al. (2008) concluded that further research is needed to examine technology impact on the role of nurses and their activities, and suggested Activity Theory as one of the potentially useful approaches. This is in line with Yen and Bakken (2012) who noted that there are more quantitative than qualitative studies in evaluating HIS usability during systems' implementation and routine use stages. Furthermore, as there is a recognised need for more qualitative types of research when studying HIS in acute healthcare contexts as such studies tend to uncover more issues around using HIS including fidelity and usability (Nguyen et al., 2014; Yen \& Bakken, 2012).

Overall, mixed and inconclusive findings from the previous studies provide a strong case for needed further research using a rich analysis lens to gain in-depth understanding of the role of HIS and in particular electronic nursing documentation systems in the immediate context of use. Hence to provide a rich lens of analysis to shed light on HIS in the context of nursing documentation, this study focuses on the mediating role of technology as a tool in the specific context of human activity; i.e., a nursing information system in an acute healthcare context and analyses this using a rich theoretical lens; i.e., Activity Theory.

\section{Activity Theory in information systems}

Given low satisfaction with IS theories around user acceptance and adoption specifically in acute healthcare nursing contexts (see for example Cresswell et al., 2010; Holden \& Karsh, 2010), we investigate the benefits of framing the situation in terms of Activity Theory.

\subsection{An overview of key concepts in Activity Theory}

Activity Theory, or cultural-historical theory of activity, (Vygotsky, 1978, English translation) was first developed in the 1920 s and 1930 s by Lev Vygosky, a Russian psychologist, together with his colleagues. The fundamental building block of the theory is a human activity involving a subject i.e. a human agent, and an object i.e. an objective or goal of activity. This subjectobject relationship is mediated by tools and signs (language/words) that essentially are linked to a culture.

Activity Theory was extended by Leontiev (2009, English translation) to describe a three layer model of human activity consisting of activity, actions and operations. Along with these, there 
is another hierarchy of motivation consisting of motive, goals, and conditions. An activity is associated with motive at the top level and can be characterized as high-level, significant and holistic. Activity can be achieved through a set of actions where each consists of operations. An action can be associated with an intention (to achieve a specific goal) and operations. An operation is a performed routine to complete the action under certain conditions.

Activity Theory was further extended by Engeström $(1987,1999)$ to include the collective characteristics of the human activity system. The extended model includes additional collective elements of rules, community and division of labour. Rules and division of labour can be explicit or implicit. Rules refer to conventions, regulations and social relations within a community while division of labour refers to the organisation of a community to enable the transformation. Therefore, rules mediate the relationship between subject and community while division of labour mediates the relationship between object and community. The mediating roles of tools, rules and division of labour are historically formed and evolve over time. Further, Engeström's structure of activity also emphasises the transformation of an object to an outcome (Engeström, 1987).

As shown in Figure 1, the structure of an individual human activity includes a subject e.g. an individual worker or member of the workplace community, tools e.g. conceptual models or devices, the rules that govern their work, and the purpose to which the subject directs their activity. This structure of individual human activity can be further extended to denote the interaction between multiple human activities where the activities share common goals and rules of division of labour.

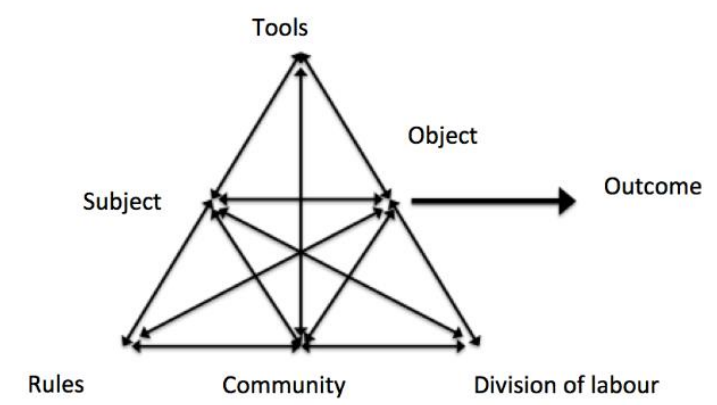

Figure 1. Structure of human activity in Activity Theory (Engeström, 1987, 1999)

Engeström (1987) described human activity as a goal oriented, tool and cultural-historically mediated. Furthermore, he added the dynamic, cultural-historical dimension to the human activity through the concepts of externalisation and internalisation. Externalisation can be described as the process of change driven by tensions and conflicts motivting changes and improvements; as a result new tools are created and introduced. Internalisaiton can be described as the process of reproduction of culture through the training of members within the community to adopt changes and fit in the new culture. These two processes are refered to as the dynamic cycle of learning and enable for both the historical continuilty and adaptation of the culture of the human activity system.

\section{2 $3.2 \quad$ Use of Activity Theory in information systems}

Some of the first instances when Activity Theory was recommended to be used for Information Systems (IS) research include by Nardi (1996: chapter 1) and Kuutti (1996: chapter 2). Both of these authors emphasise the notion of technology mediation in Activity Theory. Technology can be seen as tools or "mediators of human thought and behaviour" (Nardi, 1996: p. 7). Thus, to design an effective mediating technology solution, we should understand users' thoughts and behaviours in the context of use. Since then, Activity Theory has been embraced by IS researchers from different perspectives. Table 2 summarises the key perspectives. 


\begin{tabular}{|l|l|l|l|l|l|}
\hline Perspective & Subject & Object & Tools & Community & Advocates \\
\hline $\begin{array}{l}\text { 1. IS } \\
\text { development } \\
\text { as a human } \\
\text { activity }\end{array}$ & $\begin{array}{l}\text { The } \\
\text { developer of } \\
\text { an } \\
\text { information } \\
\text { system }\end{array}$ & $\begin{array}{l}\text { To build an } \\
\text { information } \\
\text { system }\end{array}$ & $\begin{array}{l}\text { Analysis and } \\
\text { design } \\
\text { methods, } \\
\text { computers, } \\
\text { networks, } \\
\text { programming } \\
\text { languages and } \\
\text { tools. }\end{array}$ & $\begin{array}{l}\text { Developers, } \\
\text { user } \\
\text { representatives } \\
\text { and their } \\
\text { workplace } \\
\text { environment(s) }\end{array}$ & $\begin{array}{l}\text { (Kuutti, } \\
\text { 1996: pp. } \\
\text { 14-15). }\end{array}$ \\
\hline $\begin{array}{l}\text { 2. IS as a tool } \\
\text { in various } \\
\text { human } \\
\text { activities }\end{array}$ & $\begin{array}{l}\text { The user of } \\
\text { an } \\
\text { information } \\
\text { system }\end{array}$ & $\begin{array}{l}\text { User's goals } \\
\text { (for example } \\
\text { healthcare, } \\
\text { business, } \\
\text { education, } \\
\text { entertainment } \\
\text { and social } \\
\text { networking } \\
\text { etc.) }\end{array}$ & $\begin{array}{l}\text { An } \\
\text { information } \\
\text { system(s) } \\
\text { (and other } \\
\text { tools) }\end{array}$ & $\begin{array}{l}\text { Users' } \\
\text { workplace } \\
\text { environment } \\
\text { and/or their } \\
\text { communities }\end{array}$ & $\begin{array}{l}\text { (Hashim \& } \\
\text { 2007). }\end{array}$ \\
\hline $\begin{array}{l}\text { 3. IS research } \\
\text { study as a } \\
\text { human } \\
\text { activity }\end{array}$ & $\begin{array}{l}\text { The IS } \\
\text { researcher }\end{array}$ & $\begin{array}{l}\text { To answer an } \\
\text { IS research } \\
\text { question(s) } \\
\text { and extend the } \\
\text { current human } \\
\text { knowledge }\end{array}$ & $\begin{array}{l}\text { Research } \\
\text { methodologies } \\
\text { and tools }\end{array}$ & $\begin{array}{l}\text { Research } \\
\text { environment, } \\
\text { participants, } \\
\text { their } \\
\text { organisation(s) } \\
\text { and the wider } \\
\text { community }\end{array}$ & $\begin{array}{l}\text { \& Hasan, } \\
\text { 20o6) }\end{array}$ \\
\hline
\end{tabular}

Table 2. Perspectives of using Activity Theory in IS research

With a view to examining the usability and fidelity of HIS, we are interested in the second perspective in Table 2, i.e. IS as a tool in a human activity in the healthcare context. Activity Theory has been found to be useful to explore and elicit healthcare practitioners' requirements for an information system as a tool (Häkkinen \& Korpela, 2007; Sadeghi et al., 2014) and to unpack healthcare activities when assessing e-health readiness in community hospitals in South Africa (Coleman \& Coleman, 2013). Activity Theory has also been used in investigating IS adoption in healthcare contexts. For example, factors affecting doctors' intention to adopt IS were found to include subject (human), tool (technology), and environment (organization) (JuLing et al., 2016). In the above-mentioned studies, doctors, nurses, social workers and hospital administrators were the subject; HIS was their to-be or adopted tool; and their task and work process was the objective according to Activity Theory.

Other studies (Vega-Barbas et al., 2015; Waycott et al., 2014) consider patients as the subject interacting with technology tools for their own healthcare. Waycott et al. (2014) conducted a multiple case study with 15 pregnant women with type 1 diabetes and concluded that motivated patients play an active role in aligning such interacting activity systems and adjusting their use of technology tools for their own health management.

Activity Theory has also been adopted to review research efforts in IS adoption within the healthcare domain (Sun \& Qu, 2015). These authors selected 979 papers about HIS adoption published between 1990 and 2009 from online databases including Pubmed, Medline and Embase. Using a text-mining tool and the Activity Theory lens, the authors identified different types of subjects, tools and their tasks from the abstracts of the selected papers. Their work revealed that (1) IS adoption can be examined at an individual as well as a social level, and that (2) current research tends to examine IS adoption at individual levels rather than adoption at a social level.

Our study builds on previous research in which Activity Theory was found to be a useful theoretical lens to examine IS as a tool in human activities in their immediate context of use. Particularly, we used the Activity Theory lens to examine the mediating i.e. supporting, role of a new point of care electronic documentation system in its natural, target patient care setting. 
Thus, this is one of the first studies to use Activity Theory in an acute healthcare nursing context in this fashion.

\section{Research approach}

The study reported in this paper was one component of a large multi-disciplinary longitudinal funded research program (Nguyen et al., 2015). A design science research methodology has been adopted to guide the cycles of problem/opportunity determination (relevance cycle), solution design and evaluation examine (design cycle), using the knowledge base to inform design (rigor cycle) (Hevner \& Chatterjee, 2010; Hevner et al., 2004) through the large research project. The problem addressed in the on-going research project is focused on the lack of a technology solution that is usable for nurses and reflects and responds to the complexity of nursing work (Stevenson et al., 2010). This paper reports specifically on the findings from one of the design cycles in which Activity Theory was adopted to examine the mediating role for a new Electronic Bedside Documentation System (EBDS) in an acute care context. We note that the EBDS solution was developed by an international vendor and this study is one of the first to examine the system in situ. The development of the EBDS was informed through our study including the full cycle of design science research methodology. See Table 3 below for how Hevner's et al. (2004) design science research guidelines apply in this project, i.e. in acute healthcare nursing context.

\begin{tabular}{|l|l|}
\hline $\begin{array}{l}\text { Design Science } \\
\text { Research } \\
\text { guidelines }\end{array}$ & Our application \\
\hline $\begin{array}{l}\text { Guideline 1: Design } \\
\text { as an Artefact }\end{array}$ & $\begin{array}{l}\text { The EBDS system - a sophisticated, multi-functional point of care } \\
\text { technology designed to support nurses in the delivery and documentation } \\
\text { of patient care in the acute hospital setting. }\end{array}$ \\
\hline $\begin{array}{l}\text { Guideline 2: } \\
\text { Problem Relevance }\end{array}$ & $\begin{array}{l}\text { To address the lack of a technology solution that is usable for nurses, } \\
\text { reflects and responds to the complexity of acute healthcare nursing work. }\end{array}$ \\
\hline $\begin{array}{l}\text { Guideline 3: Design } \\
\text { Evaluation }\end{array}$ & $\begin{array}{l}\text { Nurses as users were trained to use EBDS; subsequently, they used it in } \\
\text { parallel with paper documentation; finally, champion nurses used it } \\
\text { exclusively for documentation of all nursing care delivery for selected } \\
\text { patients. }\end{array}$ \\
\hline $\begin{array}{l}\text { Guideline 4: } \\
\text { Research } \\
\text { Contributions }\end{array}$ & $\begin{array}{l}\text { In this study, nurses' perspectives of the mediating role of HIS were } \\
\text { explored. }\end{array}$ \\
\hline $\begin{array}{l}\text { Guideline 5: } \\
\text { Research Rigor }\end{array}$ & $\begin{array}{l}\text { Theoretical foundations and conceptual models drawn from information } \\
\text { systems, nursing documentation and nursing process, healthcare quality } \\
\text { and safety were used to inform the development cycles to evaluate the } \\
\text { EBDS system in the acute healthcare nursing context. }\end{array}$ \\
\hline $\begin{array}{l}\text { Guideline 6: Design } \\
\text { as a Search Process }\end{array}$ & $\begin{array}{l}\text { In this project, Activity Theory concepts (subject, object, tools, } \\
\text { community, rules, division of labours) were used to guide data analysis } \\
\text { and define areas and levels of mediation. The findings will inform future } \\
\text { implementations. }\end{array}$ \\
\hline $\begin{array}{l}\text { Guideline 7: } \\
\text { Communication of } \\
\text { Research }\end{array}$ & $\begin{array}{l}\text { Internal communication: The larger research project (of which this study } \\
\text { is part of) is presented to technology and clinically-oriented users through } \\
\text { focus groups, simulations exercises, brainstorming meetings, as well as } \\
\text { technical and managerial meetings. } \\
\text { External communication: Progress and findings are reported in a book } \\
\text { chapter and peer review papers submitted to international conferences } \\
\text { and professional peer-reviewed journals in each discipline. }\end{array}$ \\
\hline
\end{tabular}

Table 3. Application of design science research guidelines to the development of EBDS (Guidelines adopted from Hevner et al., 2004) 


\subsection{Research setting}

The EBDS system is a sophisticated, multi-functional point of care technology solution designed to support nurses in the delivery and documentation of patient care in the acute hospital setting. It was designed to allow nurses to document patient care and access the care data in real time, thereby providing potential enhancement to nurses' work experience. The system was run on a server and a thin client and the frontend was on an iPad mounted at each patient bedside.

EBDS was put into an implementation for eight weeks from August to October in 2013. The implementation was conducted in two acute care wards across two sites of a single large metropolitan health service in Victoria, Australia. Human research ethics approvals were obtained from the host healthcare service provider and affiliated university prior to the commencement of the study.

The participating wards included a 25-bed general surgical ward and a 32-bed general medical and neurology ward involved over 80 nurses. Nurses were the primary end users of the system. Nurse managers were asked to provide lists of all registered and enrolled nursing staff working regularly on their wards more than one shift per week. Agency nurses and nursing staff working in the participating wards less than one shift per week were excluded from the study as these staff did not have the opportunity for training to become familiar with the system prior to use in their routine work. All staff were individually sent written information about the study and invited to attend information sessions where they were able to ask questions. On agreement to participate, all participants were then allocated a unique code to protect their identity in all research data. At the completion of data collection and prior to analysis, all potentially identifying features were removed.

The process (in the study reported in this paper) consisted of three stages. During Stage 1, the EBDS system was installed in eight beds on each ward; and nurse participants were recruited, trained and introduced to using EBDS. Stage 1 occurred over two weeks. Stage 2 was designed to integrate the EBDS system into selected nursing care processes for a sub-group of patients allocated to the beds where it was installed. During this stage the participating nurses began to adopt the system into care processes. Stage 2 occurred over three weeks. While using EBDS, nurse participants identified issues of concern related to usability and risk mitigation, these issues were then prioritized by the management committee; and in response EBDS was modified in real time by the developers. During Stage 3, the system was used exclusively for documentation of all nursing care delivery for selected patients. The participants were three nurses identified as early adopters or 'super users' from Stage 2. To ensure patient safety, a supernumerary nurse 'scribe' was employed to 'shadow' all activities performed by nurse participants in order to manually duplicate all documentation of patient data into the permanent paper records. This was a requirement from ethics and legal.

Table 4 maps the key concepts in Activity Theory to our conceptualisation of the nursing documentation activity in the acute healthcare nursing context. Nursing documentation is one of the human activities in the overall context of patient care. The overall objective is to ensure quality, safety, and efficiency of patient care, and that positive patient outcomes ensue. The EBDS system is proposed to be a new electronic tool to replace paper forms and charts to support nursing documentation activity. 


\begin{tabular}{|l|l|}
\hline Key concepts & Nursing documentation \\
\hline Subject & Nurse \\
\hline Object & $\begin{array}{l}\text { Documentation of patient care } \\
\text { Tools }\end{array}$ \\
$\begin{array}{l}\text { There is a range of tools to support nurses to communicate and document } \\
\text { charts, communication whiteboard, phones, medical equipment and other } \\
\text { clinical tools. EBDS is the new information system and is the system under } \\
\text { study. }\end{array}$ \\
\hline Community & $\begin{array}{l}\text { A community of nurses, patients, other healthcare professionals in acute care } \\
\text { setting in the hospital. }\end{array}$ \\
\hline Rules & $\begin{array}{l}\text { Documentation is required as part of nursing discipline; other rules concern } \\
\text { care process and workflows, and other hospital and broader healthcare } \\
\text { regulations. }\end{array}$ \\
\hline labour & $\begin{array}{l}\text { Distribution of work, power, and responsibilities among nurses and other } \\
\text { healthcare professionals such as doctors, pharmacists, other specialists, } \\
\text { allied health, etc. For example, nurse assesses vital signs while the medical } \\
\text { professional / doctor assesses medical progress specific to the treatment } \\
\text { under consideration. }\end{array}$ \\
\hline
\end{tabular}

Table 4. Understanding nursing documentation using key concepts of Activity Theory

\subsection{Data collection and analysis}

Focus groups and non-participant observations were used as data collection methods. During Stage 2, two focus groups (FGA and FGB) were conducted with eight nurses. At the end of Stage 3, a third focus group (FGC) was conducted with the three nurses who participated in this stage. Up to eight nurses participated in each focus group. During the focus groups, nurses were asked to reflect upon their experience with EBDS. In particular, they were asked to talk about how they use and their experiences with the system to document and deliver nursing care, what features of the technology are most useful/ unhelpful to achieve these objectives, how this new technology influenced your work in acutecare setting in the hospital (time, nursing care documentation and delivery, interactions with patients and other healthcare professionals, nursing care process, workflows,...), and/or impacted on the quality and safety of patient care. Nurses were encouraged to suggest changes. Non-participant observations of nurses' interactions with the system were also conducted. The observers followed the nurses around the wards during times pre-identified to capture 'peak use' of the system. Observers used a purpose specific semi-structured observation data collection tool (a form on an iPad) to record the date, time, location, and an audio recorded description of each interaction between the nurse and the EBDS system. The observed nurses were wearing a MP 3 recorder and were asked to speak aloud when interacting with the system. Their verbal interactions with patients and other hospital staff were also recorded during the observation session. In total, 48 hours of observation data were collected and eight participating nurses were observed during Stages 2 and 3.

This paper presents a conceptual mapping as well as empirical findings from our analysis of the collected qualitative data through the lens of Activity Theory. The data were analysed using content and thematic analysis (Braun \& Clarke, 2006; Kvale, 1996). Data analysis steps include: becoming familiar with the data, initial coding using Activity Theory concepts, identifying themes (e.g. support for goal achievement, affecting and problematic, reflecting reality), iterative coding and reviewing themes, refining themes and producing the report. In the initial coding cycle, coding nodes were pre-determined based on essential Activity Theory constituents including subject, tool, object, rule, division of labour, and community. In the subsequent coding cycles, new coding nodes were generated to code relevant expanded triangles i.e. ternary relationships between tool and other constituents (triangles adapted from Activity-Oriented Design Method, see Mwanza-Simwami, 2011; Sadeghi et al., 2014, see Table 5). Additional nodes included high and low usability, high fidelity and low fidelity; sub-nodes emerged from the observation and focus group data for example navigation, interface, efficiency, training and support, improved safety, safety concern, privacy. A combination of 
software tools including Nvivo and XL were used for data coding, data management and theme review. Nvivo was used to record the coding nodes and select and assign coded texts to the nodes, not for automated coding. The coding and theme identification was done and reviewed by the researchers. Consensus was obtained though research meetings. The Nvivo coded data grouped by initial themes were retrieved and grouped in XL for subsequent thematic analysis.

\section{Results}

As described in Section 2, Activity Theory describes the human activity as mediated by tools and its cultural-historical context. The nursing documentation activity is thus mediated by different tools through the historical continuity of how nursing activities are organised and nursing practice is carried out in the specific hospital setting. The results from this study are presented in terms of i) nurse-tool-documentation relationship and cycle of expansive learning as well as (ii) the mediating role of the EBDS.

\subsection{Nurse-tool-documentation relationship and the cycle of expansive learning}

The subject-object dialectic relationship between nurse and documentation of patient care was mediated by different tools at different stages of the implementation. During Stage 1, EBDS was introduced to nurses while they still used paper forms to document patient care data. In Stage 2, to ensure patient safety requirements (requested by the hospital management committee; ethics and legal), nurses used the system in parallel with paper forms to document patient care. Their documentation activity was mediated by both the paper forms and EBDS. The observations revealed that data entry was the primary interaction between Nurse and EBDS. Occasionally nurses used the system to check the patient's ID and vital signs. They still relied on paper forms and charts to access the patient care data. In Stage 3, 'super user' nurses used the system to document and access patient care data without paper forms for a short period of time. The interactions between the nurse and paper and EBDS as tools were found to be object-oriented, for the purpose of documenting and accessing patient data for care delivery.

According to Activity Theory, tensions and conflicts drive change, leading to the creation of new tools and to changes to the current practice; this process is refereed to as externalisation (Engeström, 1987). In this case, the EBDS system was developed in response to tensions and conflicts recognised in a wider context of nursing practice rather than only within the involved hospital. The implementation of the system demonstrates that the hospital recognised the current tensions and conflicts in using paper-documentation in acute healthcare nursing, thus the need for such as system. Externalisation was noted through nurses' sharing of comments about the need for change in their documentation practice; "biggest problems is that the educators here are wanting it to stay the say way as the paper forms, and that's reflecting on the way the system has been working. Until they embrace the change, it's not going to work." [FGB] Further, they expressed the vision that electronic nursing documentation is the way for the future: "It's the way to go, it's electronic, definitely. There's no going back" because it is about "being able to work at a fast pace" [FGA] and having everything "in one place" [FGB]. Therefore in this implementation, externalisation is manifested through the introduction of EBDS as an innovation in documentation practice.

Internalisation involves the reproduction of culture as a result of innovation (Engeström, 1987). In this case, internalisation is manifested through supporting and training nurses to use EBDS as an electronic tool in Stage 1, and to embrace associated cultural shifts in nursing documentation in Stages 2 and 3. Stage 1 was designed to install the EBDS system and train the nurse participants. Cultural shifts include significant changes from paper to electronic documentation, from delayed to real-time documentation, and a change in documentation location from nurses' station to patient bedside. As observed throughout the three Stages, clinical champions and the EBDS team were around to provide training and assistance to the participating nurses when needed. Training was found to be an important issue: Training and assistance was appreciated by the nurses: "we've had a lot of support from the researchers and the EBDS team" and "always someone here to help us, so that aspect is very good" [FGA]. 
Nurses expressed a willingness to learn to better use EBDS: "We'll just carry on doing the best we can to come to grips with it" [FGA] and "Just learn it and deal with it" [FGC]. Internalisation was manifested through nurses' overall attitude and learning towards embracing technology solution and associated cultural shifts.

\subsection{Examination of the mediating role of EBDS}

An examination of how the EBDS system mediated existing relationships revealed its potential; i.e., positive aspects, as well as areas for improvement. The mediating role of EBDS was examined in relevant ternary relationships with other constituents (adapted from MwanzaSimwami, 2011; Sadeghi et al., 2014) and a summary of findings is provided in Table 5.

\begin{tabular}{|c|c|c|c|c|}
\hline $\begin{array}{l}\text { Generic } \\
\text { Relationships }\end{array}$ & $\begin{array}{l}\text { Contextualised } \\
\text { Relationships }\end{array}$ & $\begin{array}{l}\text { Mediating role } \\
\text { of EBDS }\end{array}$ & $\begin{array}{l}\text { Facilitating } \\
\text { (Positive } \\
\text { impacts of } \\
\text { EBDS) }\end{array}$ & $\begin{array}{l}\text { Affecting } \\
\text { (Current } \\
\text { negative } \\
\text { impacts of } \\
\text { EBDS i.e. areas } \\
\text { for } \\
\text { improvement) }\end{array}$ \\
\hline $\begin{array}{l}\text { Subject, Tool, } \\
\text { and Object } \\
\text { (See sub- } \\
\text { section } 4.2 .1 \text { ) }\end{array}$ & $\begin{array}{l}\text { Nurse, EBDS, } \\
\text { and Nursing } \\
\text { documentation }\end{array}$ & $\begin{array}{l}\text { How does EBDS } \\
\text { facilitate/affect } \\
\text { nurses in nursing } \\
\text { documentation? }\end{array}$ & $\begin{array}{l}\text { EBDS's relative } \\
\text { ease of use; } \\
\text { systematic data } \\
\text { entry; useful data } \\
\text { source and } \\
\text { functionality to } \\
\text { support for care } \\
\text { delivery and } \\
\text { nursing } \\
\text { judgement; } \\
\text { improved } \\
\text { efficiency. }\end{array}$ & $\begin{array}{l}\text { Usability } \\
\text { (navigation, } \\
\text { presentation and } \\
\text { data entry } \\
\text { options). A } \\
\text { roadmap of } \\
\text { EBDS and } \\
\text { navigation. }\end{array}$ \\
\hline $\begin{array}{l}\text { Subject, Tool } \\
\text { and Division of } \\
\text { Labour } \\
\text { (See sub- } \\
\text { section 4.2.2) }\end{array}$ & $\begin{array}{l}\text { Nurse, EBDS, } \\
\text { and distribution } \\
\text { of work, power, } \\
\text { and } \\
\text { responsibilities in } \\
\text { acute care wards }\end{array}$ & $\begin{array}{l}\text { How does EBDS } \\
\text { facilitate/affect } \\
\text { nurses in } \\
\text { undertaking their } \\
\text { role, duties and } \\
\text { responsibilities } \\
\text { assigned to them? }\end{array}$ & $\begin{array}{l}\text { Functionality to } \\
\text { allocate nurses and } \\
\text { assign access } \\
\text { permission } \\
\text { accordingly; } \\
\text { retrieve patient } \\
\text { data from EBDS } \\
\text { during handover } \\
\text { (though limited). }\end{array}$ & $\begin{array}{l}\text { Lack of shift- } \\
\text { based plan }\end{array}$ \\
\hline $\begin{array}{l}\text { Tool, Rules, } \\
\text { Object } \\
\text { (See sub- } \\
\text { section 4.2.3) }\end{array}$ & $\begin{array}{l}\text { EBDS, nursing } \\
\text { discipline, } \\
\text { workflows, and } \\
\text { other hospital } \\
\text { and broader } \\
\text { healthcare } \\
\text { regulations, and } \\
\text { nursing } \\
\text { documentation }\end{array}$ & $\begin{array}{l}\text { How well does } \\
\text { EBDS-enabled } \\
\text { documentation } \\
\text { map with nursing } \\
\text { disciplines, } \\
\text { workflows, and } \\
\text { hospital } \\
\text { regulations? }\end{array}$ & $\begin{array}{l}\text { Systematic } \\
\text { documentation, } \\
\text { EBDS functions, } \\
\text { forms and charts, } \\
\text { alerts and prompts } \\
\text { were designed } \\
\text { based on the } \\
\text { nursing disciplines } \\
\text { and hospital forms } \\
\text { and charts. } \\
\text { Potential to be } \\
\text { more prompting. }\end{array}$ & $\begin{array}{l}\text { Gaps in between } \\
\text { EBDS and the } \\
\text { existing } \\
\text { documentation } \\
\text { charts, forms, } \\
\text { and paper layout } \\
\text { design. }\end{array}$ \\
\hline
\end{tabular}




\begin{tabular}{|c|c|c|c|c|}
\hline $\begin{array}{l}\text { Generic } \\
\text { Relationships }\end{array}$ & $\begin{array}{l}\text { Contextualised } \\
\text { Relationships }\end{array}$ & $\begin{array}{l}\text { Mediating role } \\
\text { of EBDS }\end{array}$ & $\begin{array}{l}\text { Facilitating } \\
\text { (Positive } \\
\text { impacts of } \\
\text { EBDS) }\end{array}$ & $\begin{array}{l}\text { Affecting } \\
\text { (Current } \\
\text { negative } \\
\text { impacts of } \\
\text { EBDS i.e. areas } \\
\text { for } \\
\text { improvement) }\end{array}$ \\
\hline $\begin{array}{l}\text { Subject, Tool } \\
\text { and } \\
\text { Community } \\
\text { (See sub- } \\
\text { section 4.2.4) }\end{array}$ & $\begin{array}{l}\text { Nurse, EBDS, } \\
\text { and hospital } \\
\text { healthcare } \\
\text { community } \\
\text { (other nurses, } \\
\text { patients, } \\
\text { healthcare } \\
\text { professionals) }\end{array}$ & $\begin{array}{l}\text { How does EBDS } \\
\text { facilitate/affect } \\
\text { nurses when } \\
\text { working with } \\
\text { other nurses and } \\
\text { the healthcare } \\
\text { community }\end{array}$ & $\begin{array}{l}\text { Nurses visited } \\
\text { patients more } \\
\text { frequently and } \\
\text { spent more time } \\
\text { with the patients; } \\
\text { potential of EBDS } \\
\text { in sharing and } \\
\text { communicating } \\
\text { patient data with } \\
\text { healthcare } \\
\text { professionals. }\end{array}$ & $\begin{array}{l}\text { Patient private } \\
\text { time might be } \\
\text { affected. There } \\
\text { may be a lack of } \\
\text { nurse-patient } \\
\text { interactions if the } \\
\text { nurse is not } \\
\text { familiar with the } \\
\text { system. }\end{array}$ \\
\hline $\begin{array}{l}\text { Community, } \\
\text { Tool, Object } \\
\text { (See sub- } \\
\text { section 4.2.5) }\end{array}$ & $\begin{array}{l}\text { Hospital } \\
\text { healthcare } \\
\text { community, } \\
\text { EBDS, and } \\
\text { nursing } \\
\text { documentation } \\
\text { (thus quality and } \\
\text { safety) of patient } \\
\text { care }\end{array}$ & $\begin{array}{l}\text { How well does } \\
\text { EBDS } \\
\text { facilitate/affect } \\
\text { communication } \\
\text { and collaboration } \\
\text { among the } \\
\text { healthcare } \\
\text { community? }\end{array}$ & $\begin{array}{l}\text { Potential data } \\
\text { sharing to support } \\
\text { collaborative care } \\
\text { and care } \\
\text { coordination. }\end{array}$ & $\begin{array}{l}\text { Need to support } \\
\text { synchronous } \\
\text { multi- } \\
\text { disciplinary care } \\
\text { coordination } \\
\text { especially in } \\
\text { emergency } \\
\text { situations. }\end{array}$ \\
\hline
\end{tabular}

Table 5. The mediating role of EBDS in key Activity Theory ternary relationships

Often, the mediating role of EBDS manifested in more than one relationship. For example, as a result of effective mapping between the system and nursing disciplines and process (Tool, Rules, and Object), EBDS also facilitated nurses to document patient care data (Subject, Tool, and Object). Therefore, the mediating role of EBDS is noted in relation to different relationships when appropriate.

\subsubsection{Subject, Tool and Object}

In the central relationship of Subject, Tool and Object, the mediating role of EBDS is concerned with how the system facilitates (or affects) nursing documentation. The mediating role of EBDS manifested through different aspects: at different levels of ease of use, forcing systematic data entry in documenting, how well EBDS forms, charts and data reflect the patient care 'reality', levels of support for nursing judgement, change the documentation location, shift to real-time documentation, and work efficiency. In Stage 2, nurses identified a number of usability issues in regard to the user interface including information navigation, screen layout, data entry options. Nurses suggested changes to improve the information presentation and data entry methods such as adding bed numbers and a menu for frequently used options. As a result of implemented changes in EBDS, nurses found the EBDS system to be easier to use in Stage 3, compared to the version used in Stage 2. For example, "the system became a lot more usable to us as the improvements - and as things changed, it definitely became more user friendly" [FGC]. Areas for further improvements include a roadmap of the complex system and better navigation mechanisms to allow them to move easily between different screens to locate and review information from multiple relevant charts simultaneously.

The EBDS system was observed to force nurses to enter patient data systematically. Nurses were required to move through all the required forms and steps, complete documentation from one patient before their next task. The EBDS bedside records were found to be a useful source of patient data that reflects care plans and delivered care: "(all is) in one place; everyone knows where it is and it doesn't move" [FGB] and "there's the patient's details, why they're here and their history. We have known in our head patients, but if you want something a lot 
more - how long ago was that operation, you can do that at the bedside, which is useful" [FGA]. Therefore, EBDS enforced systematic documentation, hence it also mediated the relationship Rules-Object. Due to the limited scope of the implementation, not all paper charts were translated into EBDS. Hence, the electronic documented data were incomplete and did not truly reflect patients' care plans and delivered care. In addition, as nurses used to colour code information in the paper charts, they found the limited grey colour of digital forms in EBDS to potentially be misleading and confusing. Gaps in between EBDS and the documentation requirements (current forms and charts) can be perceived as a limitation of the system in mediating the relationship between Rules and Object, which is affecting the Subject and Object relationship.

Nurses found EBDS to have the potential to reduce time wasted due to paper documentation, walking between patients and nurses' stations, looking for paper forms, and data loss due to misplacement of papers: "it would streamline our work so that it was quicker and more efficient" [FGA]. However, in Stage 2, their efficiency decreased because of the extra time nurses spent with learning to use EBDS and because of the usability issues, as agreed by nurses: "(there is the) potential to save time when you get used to it" [FGB]. In Stage 3, the participating nurses became familiar with the system and many usability issues had been addressed, nurses found their work efficiency increased: "in the final stage, (EBDS) definitely saved me time looking for charts" [FGC]. EBDS was found to increase efficiency in SubjectObject interactions in this final stage.

\subsubsection{Subject, Tool and Division of labour}

EBDS was observed to provide support for division of labour although it was rather limited. It allowed Nurse Unit Managers (NUM) to allocate nurses and their access permissions in the system according to their roles and responsibilities. During handover, nurses retrieved data from EBDS mostly for patient identification and occasionally for observation data. A gap was found to be the lack of shift-based plan in the system. Nurses were required to go to each patient's bedside to access the patient care plan and data. Therefore, they found it difficult to plan and prioritise their shift-based care activities for all the patients assigned to them: "so it's not really reflecting what we would really do with 12 patients" [FGC]. This can be seen as low fidelity of the system (as a tool) in facilitating the relationship between Subject and Division of labour, subsequently affecting the Subject and Object relationship.

\subsubsection{Tool, Rules, and Object}

In addition to 'forcing' nurses to systematically enter patient care data, the system EBDS generated prompts for nurses to complete missing information and provided reminders to check on patients, thus potentially improved patient safety. Particularly, nurses found the system's automatic calculation of the patient fluid balance to be useful: "you don't need to calculate the vomit, how many and how much, as you cannot always hold a calculator, EBDS saves time" (recorded observation audio). Although compared to paper forms, EBDS was found to better mediating the relationship between Rules and Object, nurses wanted the system to be "more prompting" rather than "being a mirror image of the paper forms" [FGB]. Another benefit of the EBDS prompts and alerts is that it reminds nurses about the scheduled tasks and 'forced' nurses to document them in real-time, rather then keeping information in head or paper notes and entering it into the system later, often at the end of each shift. Realtime documentation at patient bedside is important to ensure accurate and complete data that reflects the delivered patient care (i.e. the reality). Fidelity of the system in the above examples is manifested through enabling better practice, i.e. ensuring systematic documentation and preventing care delays or omissions.

\subsubsection{Subject, Tool and Community}

In regard to the Subject, Tool and Community relationship, EBDS appeared to affect the nursepatient interactions. It 'forced' nurses to document patient care data at the patient bedside; as a result they visited patients more frequently and spent more time with the patients. While, this could potentially increase nurse-patient interactions and improve patient safety, however 
a number of concerns were also noted. As nurses were not familiar with the system, their focus was 'fixed' on the screen rather than on the interaction with patients. In addition, nurses felt that bedside documentation could be an intrusion on patient's privacy "I felt like an intrusion yesterday when I was entering stuff and they had visitors, or she had a phone call. I'm standing there and I feel like I'm eavesdropping" [FGA].

Further in regard to the Subject, Tool and Community relationship, the participating nurses also recognised the potential of EBDS in sharing and communicating patient data with other healthcare professionals if the system is integrated with other systems. "I think once clinicians get on board, I think it will potentially save a lot of time for them as well...whoever wants to access our kind of documentation, I think it would just be so much easier having everything in one place, and only that one place. Everyone can come to it" [FGC]. Therefore, EBDS has the potential to support the relationship between Community and Object through providing information required for collaborative care between different clinical disciplines.

\subsubsection{Community, Tool and Object}

In addition to the above mentioned potential of the system to facilitate collaboration care between healthcare practitioners, there was a concern about the system being incapable to provide support for synchronous multi-disciplinary care coordination. Nurses identified the central data access point of the system as a potential problem in complex emergency scenarios such as MET (Medical Emergency Team) calls: “(with paper) someone's got the history, someone's got the obs chart, someone's got something else, whereas if it's all just on that system, I think it would be difficult if someone's trying to input information while someone's trying to look up information" [FGC].

\section{Discussion and Conclusion}

Nursing documentation is a complex human activity. It is object-oriented toward documenting and providing complete and accurate records of patient data and delivered care, partly due to legal requirements. Data retrieved from the records are important to achieve high quality, safe care delivery, process efficiency, and positive patient outcomes. In current practice, the documentation activity has been mediated by paper forms and records. The new tool EBDS was introduced. For a defined period of the implementation, we conducted this study using the lens of Activity Theory to facilitate a rich understanding of the role of the system in mediating nurses around documentation of patient care data in acute care wards.

The introduction of EBDS to acute care can be seen as an externalisation in response to the need for better technology solutions to support nurses as recognised within the nursing disciplines (Mills et al., 2013; Stevenson et al., 2010). As revealed in this implementation, the internalisation led to cultural shifts in nursing documentation. The nurse-documentation relationship was mediated by the new tool (EBDS): change to their documentation location leading to more frequent visits to patients, time duration with patients, systematic data entry, real-time documentation, better support for nursing judgement, reduced time waste in looking for paper forms etc. A number of potential benefits as well as usability issues were identified. Having identified various usability issues of the tool (e.g. user interface issues and lack of support for shift-based care plan), nurses suggested changes during the EBDS implementation. This demonstrates the dynamics of the internalisation process when EBDS and nurses' activities are appropriated to reproduce the new EBDS-enabled documentation practice (Allen et al., 2011). The study also highlights the active participation of the subject in this central Subject, Tool and Object relationship of the human activity system.

Previous research tends to examine technology adoption at the individual rather than social level (Sun \& Qu, 2015). In this study, the mediating role of the tool in the relationship with community elements was also observed. Fidelity of the system to nursing discipline and practice can be examined through the mediating role of the system in terms of how it reflects rules, division of labour, its potential to support communication and collective care between nurses and other healthcare professionals in the hospital community. Low fidelity could be 
seen, for example, through the lack of a shift-based plan and of support for synchronous multidisciplinary care coordination. The Community, Tool, and Object relationship needs further investigation as it involves the mediating elements (tool and community) in the object-oriented human activity. Further, it was found that the mediating role of the system appeared to affect different key relationships in the Activity Theory as the elements are interconnected. For example, the relationship subject-object is mediated by the tool (usability) as well as by how well the tool reflects rules and division of labour in the organisation (fidelity).

During this implementation, EBDS was used by nurses (end users) and as a stand-alone system, not integrated with other systems nor used by other healthcare professionals in the hospital. Therefore, the mediating role of the system in the other community relationships (not involving nurses as subject) was rather limited and not the focus of the study. Future research will serve to address these aspects in detail. Other limitations are briefly noted: It is a single case study that took place in two acute care wards, thus the findings are indicative and useful, but cannot be universally generalised. Further, nurses' individual/moderating factors such as age, gender, backgrounds, technology competency, and years of experience were not included in this analysis. In our future work, we will also expand our analysis to examine in detail moderating variables such as relative experience of nurses with technology as well as age and gender. Other technical and organisational aspects such as network connection, data security, patient safety and risk of infection were not part of this study.

In summary, the paper offers an examination of the mediating role for a nursing information system during an implementation in a naturalistic acute care hospital context. The study demonstrates an application of Activity Theory in Information Systems in a healthcare setting. The theoretical lens of Activity Theory reveals a socio-technical dialectic story of how the new nursing documentation culture and practice emerges, socially constructed and technically mediated. Activity Theory was found to be useful to unpack the issues around usability at the Nurse-Tool-Documentation, and fidelity around the three social constituents including Rule, Community and Division of Labour. Further, Activity Theory is significantly rich to enable the dynamic and complex operations within an acute healthcare nursing context to be examined in depth. Hence, this study has significant implications for both theory and practice.

The paper contributes to theory by being one of the first studies to incorporate Activity Theory as a theoretical lens of enquiry in the context of acute healthcare nursing with technology implementation. Activity Theory was found to be useful in examining technology impact in the context of human activities especially during a social change, through their interactions with existing and new tools and the community of practice toward their objective in a specific socioorganisational context. In this way we have also addressed in some fashion a key void as noted at the start of the paper; namely, the need for a rich analytic lens to gain an in-depth understanding of HIS in nursing contexts. There exist several opportunities for future research to integrate Activity Theory with other Information Systems theories to better conceptualise and evaluate the acceptance, use, and effectiveness of information system as a mediating/enabling tool for human activity system. For example, we believe that combining Activity Theory with theories like Unified Theory of Acceptance and Use of Technology (V. Venkatesh et al., 2003; Viswanath Venkatesh et al., 2012), Information Systems success model (DeLone \& McLean, 2003), and effective use of information systems (Burton-Jones \& Grange, 2013) will enable a rich and full analysis to ensue which will in turn serve to unpack deep and far reaching implications.

In summary then, we note that given the dynamic and complex nature of operations in an acute healthcare nursing context, Activity Theory provides a useful and rich lens to systematically analyse critical interactions. However, we believe an even more powerful analysis will ensue if Activity Theory is combined with other IS theories and plan to investigate this in our future research.

In terms of practical implications, the study strongly suggests the importance of engaging nurses in technology implementation, training and change management. Nurses should take active participation in the expansive learning process when new patient care data, systems and 
practices are appropriated at both individual and community levels. Therefore, practitioner engagement is critical and understanding how nurses may modify/adapt care path practice using the technology is an essential part of this. As this is an important finding, our future work will unpack this further.

\section{Acknowledgement}

The authors would like to thank Epworth HealthCare and the research team including, Prof Bridie Kent, Prof Mari Botti, A/Prof Bernice Redley, Peter Haddad and Dr. Imran Muhammad. We are also indebted to the company SmartWard for their support.

\section{References}

Ackerman, S. L., Tebb, K., Stein, J. C., Frazee, B. W., Hendey, G. W., Schmidt, L. A., \& Gonzales, R. (2012). Benefit or burden? A sociotechnical analysis of diagnostic computer kiosks in four California hospital emergency departments. Social science \& medicine, 75(12), 2378-2385. doi: http://dx.doi.org/10.1016/j.socscimed.2012.09.013

Aktharsha, U. S., \& Anisa, H. (2011). Impact of Information Technology on Nursing Practices. IUP Journal of Information Technology, 7(2), 33-46.

Allen, D., Karanasios, S., \& Slavova, M. (2011). Working with activity theory: Context, technology, and information behavior. Journal of the American Society for Information Science \& Technology, 62(4), 776-788. doi: 10.1002/asi.21441

American College of Physicians and American EHR Partners. (2013). Challenges with Meaningful Use: EHR Satisfaction \& Usability Diminishing, Survey of Clinicians: User satisfaction with electronic health records has decreased since 2010. from http://conference.himss.org/himss13/pdfs/61.pdf

Ammenwerth, E., Rauchegger, F., Ehlers, F., Hirsch, B., \& Schaubmayr, C. (2011). Effect of a nursing information system on the quality of information processing in nursing: An evaluation study using the HIS-monitor instrument. International Journal of Medical Informatics, 8o(1), 25-38. doi: http://dx.doi.org/10.1016/j.ijmedinf.2010.10.010

Australian Nursing Federation. (2009). Ensuring Quality, Safety and Positive Patient Outcomes. Why Investing in Nursing Makes Sense.

Banner, L., \& Olney, C. M. (2009). Automated clinical documentation: Does it allow nurses more time for patient care. CIN - Computers Informatics Nursing, 27(2), 75-81. doi: 10.1097/NCN.obo13e318197287d

Blair, W., \& Smith, B. (2012). Nursing documentation: frameworks and barriers. Contemporary Nurse, 41, $160+$.

Braun, V., \& Clarke, V. (2006). Using thematic analysis in psychology. . Qualitative Research in Psychology, 3(2), pp. 77-101. .

Burton-Jones, A., \& Grange, C. (2013). From use to effective use: a representation theory perspective. Information Systems Research, 24(3), pp. 632-658. doi: doi:10.1287/isre.1120.0444

Carayon, P., Cartmill, R., Blosky, M. A., Brown, R., Hackenberg, M., Hoonakker, P., .. . Walker, J. M. (2011). ICU nurses' acceptance of electronic health records. Journal of the American Medical Informatics Association, 18(6), 812-819. doi: 10.1136/amiajnl-2010000018

Coleman, A., \& Coleman, M. F. (2013). Activity Theory Framework: A Basis for E-Health Readiness Assessment in Health Institutions. Journal of Communication, 4(2), pp. 95100. 
Cornell, P., Riordan, M., \& Herrin-Griffith, D. (2010). Transforming Nursing Workflow, Part 2: The Impact of Technology on Nurse Activities. Journal of Nursing Administration, 4O(10), pp. 432-439. doi: 109ob1013e3181f1092eb1093f.

Courtney, K., Demiris, G., \& Alexander, G. (2005). Information technology: changing nursing processes at the point-of-care. Nursing Administration Quarterly, 29(4), 315-2322

Crawford, K., \& Hasan, H. (2006). Demonstrations of the Activity Theory Framework for Research in Information Systems. 2006, 13(2). doi: 10.3127/ajis.v13i2.40

Cresswell, K. M., Worth, A., \& Sheikh, A. (2010). Actor-Network Theory and its role in understanding the implementation of information technology developments in healthcare. BMC medical informatics and decision making, 1O(1), 67.

Darbyshire, P. (2004). 'Rage against the machine?': Nurses' and midwives' experiences of using computerized patient information systems for clinical information. Journal of Clinical Nursing, 13(1), 17-25.

de Veer, A. J. E., \& Francke, A. L. (2010). Attitudes of nursing staff towards electronic patient records: A questionnaire surveyOriginal Research Article. International Journal of Nursing Studies, 47(7), p. 846-854.

DeLone, W. H., \& McLean, E. R. (2003). The DeLone and McLean Model of Information Systems Success: A Ten-Year Update. Journal of Management Information Systems, 19(4), pp 9-30.

Dowding, D., Mitchell, N., Randell, R., Foster, R., Lattimer, V., \& Thompson, C. (2009). Nurses' use of computerised clinical decision support systems: a case site analysis. Journal of Clinical Nursing, 18(8), 1159-1167.

Eley, R., Fallon, T., Soar, J., Buikstra, E., \& Hegney, D. (2009). Barriers to use of information and computer technology by Australia's nurses: a national survey. Journal of Clinical Nursing, 18(8), 1151-1158.

Engeström, Y. (1987). Learning by expanding: An activity-theoretical approach to developmental research. Helsinki: Orienta-Konsultit.

Engeström, Y. (1999). Outline of three generations of activity theory Retrieved 27/07/2015, from http://www.bath.ac.uk/research/liw/resources/Models and principles of Activity Theory.pdf

Fichman, R. G., Kohli, R., \& Krishnan, R. (2011). The Role of Information Systems in Healthcare: Current Research and Future Trends. Information Systems Research, 22(3), 419-428. doi: 10.1287/isre.1110.0382

Gough, R., Ballardie, R., \& Brewer, P. (2014). New technology and nurses. Labour \& Industry: a journal of the social and economic relations of work, 24(1), 9-25. doi: 10.1080/10301763.2013.877118

Häkkinen, H., \& Korpela, M. (2007). A participatory assessment of IS integration needs in maternity clinics using activity theory. International Journal of Medical Informatics, 76(11-12), 843-849. doi: http://dx.doi.org/10.1016/j.ijmedinf.2006.11.003

Hashim, N., \& Jones, M. L. (2007). Activity theory: a framework for qualitative analysis. Paper presented at the 4th International Qualitative Research Convention (QRC), Malaysia.

Häyrinen, K., Saranto, K., \& Nykänen, P. (2008). Definition, structure, content, use and impacts of electronic health records: a review of the research literature. International Journal of Medical Informatics, 77(5), 291-304.

Hegney, P. D., Buikstra, E., Eley, R., Fallon, T., Gilmore, V., \& Soar, J. (2007). Nursing and information technology: Final report.: Australian Nursing Federation, http://www.anf.org.au/it_project/. 
Hevner, A., \& Chatterjee, S. (2010). Design Research in Information Systems: Theory and Practice (1st ed.): Springer.

Hevner, A., March, S., Park, J., \& Ram, S. (2004). Design Science in Information Systems Research. MIS Quarterly, 28(1), pp. 75-105.

Holden, R. J., \& Karsh, B.-T. (2010). The Technology Acceptance Model: its Past and its Future in Health Care. Journal of biomedical informatics, 43(1), 159 . doi: 10.1016/j.jbi.2009.07.002

Hoonakker, P. L. T., Carayon, P., Brown, R. L., Cartmill, R. S., Wetterneck, T. B., \& Walker, J. M. (2013). Changes in end-user satisfaction with Computerized Provider Order Entry over time among nurses and providers in intensive care units. Journal of the American Medical Informatics Association, 2O(2), 252-259. doi: 10.1136/amiajnl-2012-001114

International Organization for Standardization. (1998). International Standard ISO 9241-11 Ergonomic requirements for office work with visual display terminals (VDTs) - Part 11: Guidance on usability, https://www.iso.org/obp/ui/ - iso:std:iso:9241:-11:ed1:v1:en: Technical Committee ISO/TC 159, Ergonomics, Subcommittee SC 4, Ergonomics of human-system interaction.

Jeskey, M., Card, E., Nelson, D., Mercaldo, N. D., Sanders, N., Higgins, M. S., . . Miller, A. (2011). Nurse adoption of continuous patient monitoring on acute post-surgical units: managing technology implementation. Journal of nursing management, 19(7), 863-875. doi: $10.1111 / \mathrm{j} \cdot 1365-2834.2011 .01295 \cdot \mathrm{x}$

Ju-Ling, H., Rai-Fu, C., Hsiao, J.-L., \& Chen, R.-F. (2016). Critical factors influencing physicians' intention to use computerized clinical practice guidelines: an integrative model of activity theory and the technology acceptance model. BMC Medical Informatics \& Decision Making, 16, 1-15. doi: 10.1186/s12911-016-0241-3

Koppel, R., Metlay, J. P., Cohen, A., \& et al. (2005). Role of computerized physician order entry systems in facilitating medication errors. The Journal of the American Medical Association, 293(10), 1197-1203. doi: 10.1001/jama.293.10.1197

Kossman, S. P. (2006). Perceptions of impact of electronic health records on nurses' work. Studies in health technology and informatics, 122, 337-341.

Kuutti, K. (1996). Activity Theory as a potential framework for human-computer interaction research. In B. A. Nardi (Ed.), Context and Consciousness: Activity Theory and HumanComputer Interaction (Chapter 2, pp. 9-22). MA, USA: Massachusetts Institute of Technology Cambridge, MIT Press.

Kvale, S. (1996). Interviews: an introduction to qualitative research interviewing. Thousand Oaks, Calif.: Sage Publications.

Lærum, H., Karlsen, T. H., \& Faxvaag, A. (2004). Use of and attitudes to a hospital information system by medical secretaries, nurses and physicians deprived of the paper-based medical record: A case report. BMC Medical Informatics and Decision Making, 4. doi: 10.1186/1472-6947-4-18

Lau, F., Kuziemsky, C., Price, M., \& Gardner, J. (2010). A review on systematic reviews of health information system studies. Journal of the American Medical Informatics Association, 17(6), 637-645. doi: 10.1136/jamia.2010.004838

Lee, T.-T., Mills, M. E., Bausell, B., \& Lu, M.-H. (2008). Two-stage evaluation of the impact of a nursing information system in Taiwan. International Journal of Medical Informatics, 77(10), 698-707. doi: http://dx.doi.org/10.1016/j.ijmedinf.2008.03.004

Nguyen, L., Haddad, P., Moghimi, H., Coleman, K., Redley, B., Botti, M., \& Wickramasinghe, N. (2015). Developing an Information System for Nursing in Acute Care Contexts Paper presented at the PACIS 2015 Proceedings of the 19th Pacific Asia Conference on Information Systems, Singapore. http://aisel.aisnet.org/pacis2015/219 
Leontiev, A. N. (2009). Problems of the Development of Mind. Ohio, USA: Marxists Internet Archive.

Lin, H.-C., Chiou, J.-Y., Chen, C.-C., \& Yang, C.-W. u. n. e. t. (2016). Understanding the impact of nurses' perception and technological capability on nurses' satisfaction with nursing information system usage: A holistic perspective of alignment. Computers in Human Behavior, 57, 143-152. doi: 10.1016/j.chb.2015.12.001

Meijden, M. J. V. D., Tange, H. J., Troost, J., \& Hasman, A. (2003). Determinants of success of inpatient clinical information systems: a literature review. Journal of the American Medical Informatics Association, 10(3), 235-243.

Miller, A., Scheinkestel, C., \& Steele, C. (2009). The effects of clinical information presentation on physicians' and nurses' decision-making in ICUs. Applied Ergonomics, 4O(4), p. 753761.

Mills, J., Chamberlain-Salaun, J., Henry, R., Sando, J., \& Summers, G. (2013). Nurses in Australian acute care settings: experiences with and outcomes of e-health. An integrative review. International Journal of Management \& Information Technology, 2(2), pp. 18

Moody, L. E., Slocumb, E., Berg, B., \& Jackson, D. (2004). Electronic health records documentation in nursing: nurses' perceptions, attitudes, and preferences. CIN: Computers, Informatics, Nursing, 22(6), 337-344.

Mwanza-Simwami, D. (2011). AODM as a framework and model for characterising learner experiences with technology. Journal of e-Learning and Knowledge Society, 7(3), 7585.

Nakamura, M. M., Ferris, T. G., DesRoches, C. M., \& Jha, A. K. (2010). Electronic health record adoption by Children's Hospitals in the United States. Archives of Pediatrics and Adolescent Medicine, 164(12), 1145-1151. doi: 10.1001/archpediatrics.2010.234

Nardi, B. A. (1996). Activity Theory and Human Computer Interaction In B. A. Nardi (Ed.), Context and Consciousness: Activity Theory and Human-Computer Interaction (Chapter 1, pp. 4-8). Cambridge: Massachusetts Institute of Technology Cambridge, MIT Press.

Nguyen, L., Bellucci, E., \& Thuy, N. L. (2014). Electronic health records implementation: an evaluation of information system impact and contingency factors. International Journal of Medical Informatics, 83(11), pp: 779-796. .

Novak, L. L., Holden, R. J., Anders, S. H., Hong, J. Y., \& Karsh, B.-T. (2013). Using a sociotechnical framework to understand adaptations in health IT implementation. International Journal of Medical Informatics, 82(12), e331-e344. doi: http://dx.doi.org/10.1016/j.ijmedinf.2013.01.009

Rafferty, A. M., Clarke, S. P., Coles, J., Ball, J., James, P., McKee, M., \& Aiken, L. H. (2007). Outcomes of variation in hospital nurse staffing in English hospitals: Cross-sectional analysis of survey data and discharge records. International Journal of Nursing Studies, 44(2), 175-182. doi: 10.1016/j.ijnurstu.2006.08.003

Sadeghi, P., Andreev, P., Benyoucef, M., Momtahan, K., \& Kuziemsky, C. E. (2014). Activity Theory Driven System Analysis of Complex Healthcare Processes. Paper presented at the Proceedings of Twenty Second European Conference on Information Systems ECIS'2014 Tel Aviv. http://aisel.aisnet.org/ecis2014/proceedings/tracko9/15

Shaban, R. (2005). Theories of clinical judgment and decision-making: A review of the theoretical literature. Australasian Journal of Paramedicine, 3(1).

Staggers, N., Weir, C., \& S., P. (2008). Patient Safety and Health Information Technology: Role of the Electronic Health Record. In e. In: Hughes RG (Ed.), Patient Safety and Quality: 
An Evidence-Based Handbook for Nurses (Chapter 47, pp. 91-133). Rockville, MD, US: Agency for Healthcare Research and Quality.

Stevenson, J., Nilsson, G., Petersson, G., \& Johanssson, P. (2010). Nurses' experience of using electronic patient records in everyday practice in acute/inpatient ward settings: a literature review. Health Informatics Journal, 16(1), 63-72.

Sun, J., \& Qu, Z. (2015). Understanding health information technology adoption: A synthesis of literature from an activity perspective. Information Systems Frontiers, 17(5), 11771190. doi: 10.1007/s10796-014-9497-2

Thompson, C., \& Dowding, D. (2002). Clinical decision making and judgement in nursing. London: Churchill Livingstone.

Tilahun, B. B. T. u.-m. d., \& Fritz, F. (2015). Comprehensive Evaluation of Electronic Medical Record System Use and User Satisfaction at Five Low-Resource Setting Hospitals in Ethiopia. Journal of Medical Internet Research, 17(5), 1-1. doi: 10.2196/medinform.4106

Timby, B. K. (2009). Nursing process Fundamental Nursing Skills and Concepts (9th ed., Chapter 2).

Vatnøy, T. K., Vabo, G., \& Fossum, M. (2014). A Usability Evaluation of an Electronic Health Record System for Nursing Documentation Used in the Municipality Healthcare Services in Norway. In F. F.-H. Nah (Ed.), HCI in Business: First International Conference, HCIB 2014, Held as Part of HCI International 2014, Heraklion, Crete, Greece, June 22-27, 2014. Proceedings (pp. 690-699). Cham: Springer International Publishing.

Vega-Barbas, M., Pau, I., Martín-Ruiz, M. L., \& Seoane, F. (2015). Adaptive Software Architecture Based on Confident HCI for the Deployment of Sensitive Services in Smart Homes. Sensors (14248220), 15(4), 7294-7322. doi: 10.3390/s150407294

Venkatesh, V., Morris, M. G., Davis, F. D., \& Davis, G. B. (2003). User Acceptance of Information Technology: Toward a Unified View. MIS Quarterly, 27, pp. 425-478.

Venkatesh, V., Thong, J. Y. L., \& Xin, X. (2012). Consumer Acceptance and Use of Information Technology: Extending the Unified Theory of Acceptance and Use of Technology. MIS Quarterly, 36(1), pp: 157-178.

Vygotsky, L. S. (1978). Mind and society: The development of higher mental processes. Cambridge, MA: Harvard University Press.

Waycott, J., Scheepers, R., Davis, H., Howard, S., \& Sonenberg, L. (2014). The individual in multiple interacting activity systems: IT-supported diabetes management. Information Technology \& People, 27(4), 463-481. doi: 10.1108/ITP-11-2013-0195

Weinhara, M., Stoicu-Tivadar, L., \& Dagres, C. (2009). Early stage testing of user's satisfaction after implementation of a central electronic health record (EHR) system in Serbia. Journal on Information Technology in Healthcare, 7(2), 127-133.

Westbrook, J. I., Ling, L., Georgiou, A., Paoloni, R., \& Cullen, J. (2013). Impact of an electronic medication management system on hospital doctors' and nurses' work: a controlled prepost, time and motion study. Journal of the American Medical Informatics Association, 2O(6), 1150-1158. doi: 10.1136/amiajnl-2012-001414

Whittaker, A. A., Aufdenkamp, M., \& Tinley, S. (2009). Barriers and facilitators to electronic documentation in a rural hospital. Journal of Nursing Scholarship, 41(3), 293-300. doi: 10.1111/j.1547-5069.2009.01278.x

Yen, P.-Y., \& Bakken, S. (2012). Review of health information technology usability study methodologies. Journal of the American Medical Informatics Association : JAMIA, 19(3), 413-422. doi: 10.1136/amiajnl-2010-000020 
Copyright: (C) 2017 Nguyen \& Wickramasinghe. This is an open-access article distributed under the terms of the Creative Commons Attribution-NonCommercial 3.0 Australia License, which permits non-commercial use, distribution, and reproduction in any medium, provided the original author and AJIS are credited.

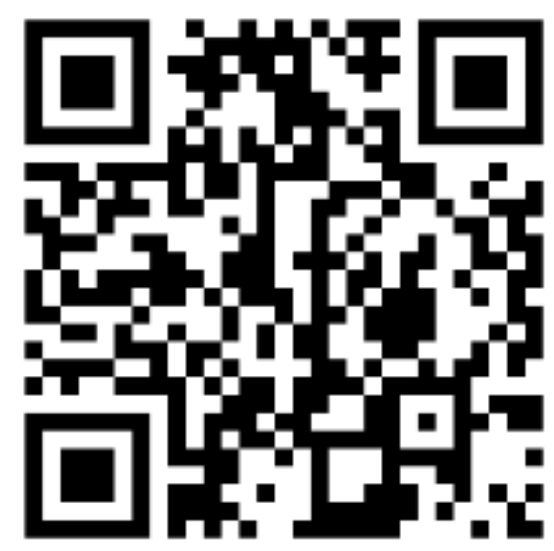

